Appl. Phys. B 49, 145-148 (1989)

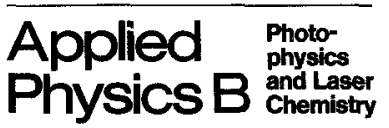

(C) Springer-Verlag 1989

\title{
Tunable UV Laser Photolysis of Organometallics with Product Detection by Laser Mass Spectroscopy: Trimethylaluminum
}

\author{
Th. Beuermann and M. Stuke \\ Max-Planck-Institut für biophysikalische Chemie, Postfach 2841, \\ D-3400 Göttingen, Fed. Rep. Germany
}

Received 21 December 1988/Accepted 9 March 1989

\begin{abstract}
We use tunable UV laser light in the region $200-320 \mathrm{~nm}$, produced by frequency doubling the output of a dye laser, for the decomposition of organometallic compounds. This method has been applied to TMA, trimethylaluminum $\mathrm{Al}\left(\mathrm{CH}_{3}\right)_{3}$. Only the TMA monomer absorbs UV light for $\lambda>220 \mathrm{~nm}$. TMA decomposes by one-photon absorption mainly into two channels: aluminum atoms $\mathrm{Al}$ plus organic fragments, and aluminummonomethyl $\mathrm{AlCH}_{3}$ molecules plus organic fragments. The ratio $[\mathrm{Al}] /\left[\mathrm{AlCH}_{3}\right]$ is wavelength dependent. We present a mechanism to explain the photolysis of trimethyl compounds of group III elements (Al, Ga, In).
\end{abstract}

PACS: $81.15,82.50$

Organometallic compounds are widely used as a source of elements generated upon exposure to energy, which may be thermal or energetic beams in the form of photons [1-10], electrons [11,12] or ions [13-16]. We describe an experiment, in which we use tunable UV laser photons of precisely defined energy for the decomposition of gaseous organometallics, namely $\mathrm{Al}\left(\mathrm{CH}_{3}\right)_{3}$. Our results show how organometallics of the trimethyl type (Al, Ga, In) interact with UV (laser) light.

\section{Experimental Setup}

A detailed description of the experimental setup can be found in [17]. A tunable UV laser light source photolyses the compound under investigation. Tunable UV output is generated by frequency doubling (SHG) the output of a $\mathrm{XeCl}$ excimer laser pumped dye laser in a $\beta$-barium-borate crystal (BBO). With this arrangement it is possible to tune the photolysis laser wavelength between 205 and $320 \mathrm{~nm}$ [18]. Moreover, one can cover the range 200-207 $\mathrm{nm}$ by sum frequency generation (SFG) [18]. Photolysis at $193 \mathrm{~nm}$ was performed by using an ArF excimer laser.
We use a weakly focussed $\mathrm{KrF}$ excimer laser $(\lambda=248 \mathrm{~nm})$ to detect the photoproducts by nonresonant two-photon ionization similar to the detection of $\mathrm{GaCH}_{3}$ as a photoproduct of trimethylgallium described earlier [8]. Alternatively, photoproducts can be detected by resonant multiphoton ionization (REMPI). Applying this technique, it was shown [6] that $\mathrm{AlCH}_{3}$ is a photoproduct of TMA.

The data presented here were obtained by exposing TMA molecules (Alfa Ventron) in the ionization region of a laser time-of-flight mass spectrometer to the UV laser light source described above at a pressure of $10^{-4}$ Torr. Then, after a time delay of $200 \mathrm{~ns}$, the neutral photoproducts were ionized by a $\mathrm{KrF}$ laser.

\section{Results}

\subsection{Absorption Spectrum of TMA}

We used a $1.5 \mathrm{~m}$ long cuvette with quartz windows and the frequency doubled dye laser as UV source to measure the absorption spectrum of TMA, which is shown in Fig. 1. The structureless spectrum in the far UV region points to a dissociative continuum of TMA. The cross section begins to rise at about $250 \mathrm{~nm}$ until 


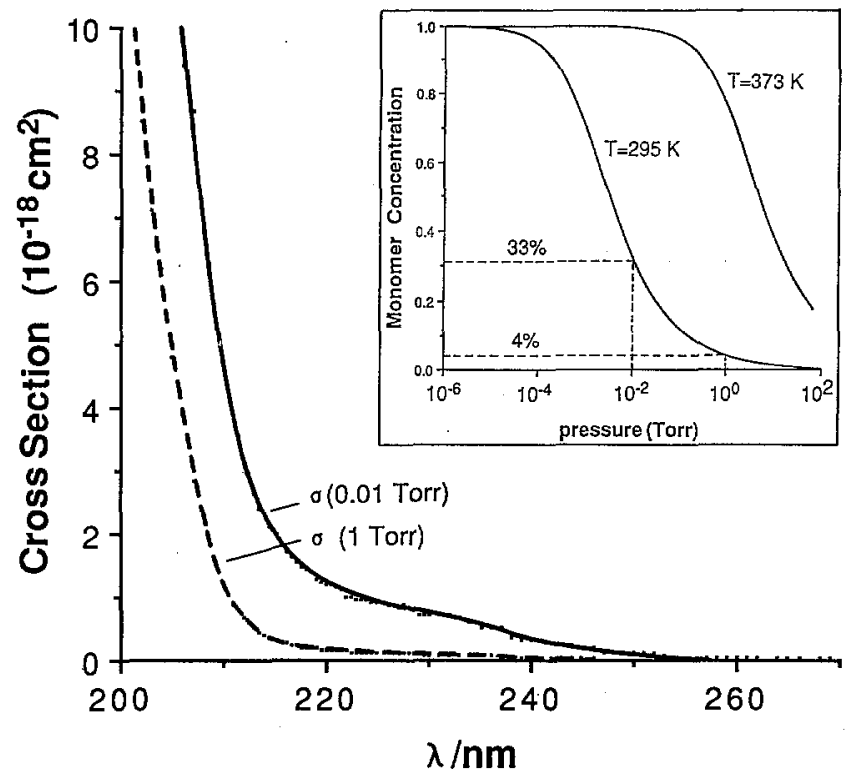

Fig. 1. UV absorption spectrum of TMA for a pressure of 0.01 Torr and 1 Torr, respectively. $\sigma$ denotes the weighted average of $\sigma$ (TMA monomer) and $\sigma$ (TMA dimer). Insert: Pressure dependence of the monomer concentration in TMA for a temperature of $295 \mathrm{~K}$ and $373 \mathrm{~K}$ (the curves were calculated using the equilibrium constant given in [19])

$220 \mathrm{~nm}$, where a new channel seems to open. The cross section is pressure dependent due to dimer formation. For a given temperature, the monomer/dimer ratio strongly depends on the pressure (insert of Fig. 1) [19]. For example, at room temperature the monomer fraction in TMA amounts to only $4 \%$ at $p=1$ Torr while is $33 \%$ at $p=0.01$ Torr (see insert), i.e. by changing the pressure from 1 Torr to 0.01 Torr the monomer fraction is multiplied by a factor 8 . For $\lambda>220 \mathrm{~nm}$ only the monomer absorbs. This can be seen from Fig. 2, where the ratio of the cross sections at $p=0.01$ Torr and $p=1$ Torr is plotted versus laser wavelength, showing an asymptotic approach to the predicted value $\sigma(0.01$ Torr $) / \sigma(1$ Torr $)=8$. Here $\sigma$ denotes the weighted average of the individual $\sigma$ 's of the monomer and the dimer.

\subsection{Photolysis of $T M A$}

Typical time-of-flight mass spectra of TMA at $\lambda=193 \mathrm{~nm}$ (ArF) can be seen in Fig. 3. Ions generated by the photolysis laser alone (top trace) are $\mathrm{Al}^{+}$and $\mathrm{Al}\left(\mathrm{CH}_{3}\right)_{2}^{+}$. The detection laser $(\mathrm{KrF})$ itself generates only a small amount of $\mathrm{Al}^{+}$(bottom trace). If the detection laser is triggered after a suitable delay of $\Delta t$ $=10.2 \mu \mathrm{s}$ with respect to the photolysis laser, the mass spectrum shown in the middle trace is obtained. In addition to the ions from the top trace, $\mathrm{AlCH}_{3}^{+}$and $\mathrm{Al}^{+}$ions are detected, due to the corresponding neutral species. Other photoproducts were not detected. The

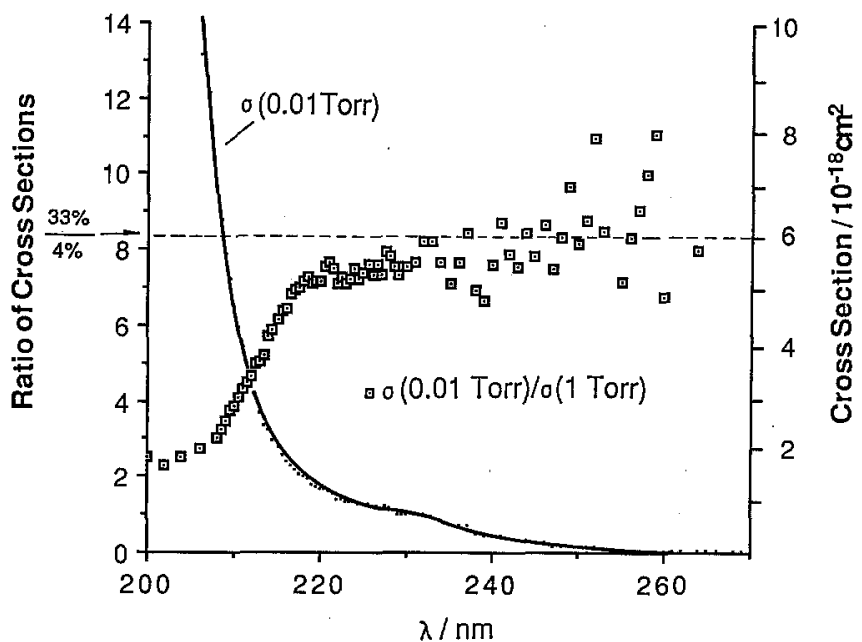

Fig. 2. Ratio of the UV absorption cross sections at 0.01 Torr and 1 Torr as a function of the wavelength. The cross section for 0.01 Torr is plotted for comparison

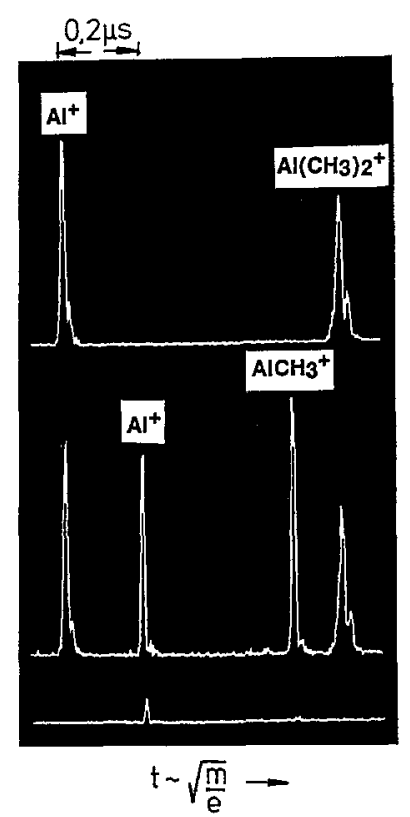

Fig. 3. Ion time-of-flight signal of trimethylaluminum $\mathrm{Al}\left(\mathrm{CH}_{3}\right)_{3}$, induced by the photolysis laser at $193 \mathrm{~nm}$ alone (top trace), and after ionization of neutral species, formed by the photolysis laser, by a weakly focussed $\mathrm{KrF}$ excimer laser (detection laser) delayed by $200 \mathrm{~ns}$ (middle trace). The control experiment, with the detection laser alone, is shown in the bottom trace (see text for details)

enhancement of the $\mathrm{Al}^{+}$and $\mathrm{AlCH}_{3}^{+}$peaks with respect to the background (bottom trace) is a measure for the relative amount of the corresponding neutral fragments produced by the photolysis laser. The above-mentioned enhancement divided by the number of photons per laser pulse gives the relative ion yield $Y$ of a photoproduct. The $\mathrm{Al}^{+}$and $\mathrm{AlCH}_{3}^{+}$signals depend linearly upon the photolysis laser energy, a 


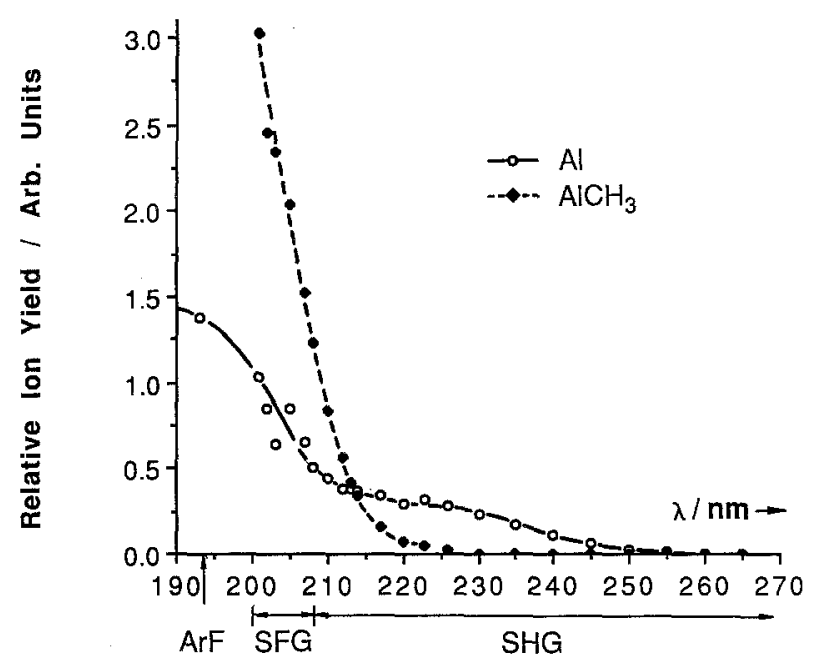

Fig. 4. Relative ion yields of $\mathrm{Al}$ and $\mathrm{AlCH}_{3}$ as a function of the photolysis laser wavelength

fact, which strongly suggests that TMA decomposes by a one-photon process. The obtained yields $Y\left(\mathrm{Al}^{+}\right)$and $Y\left(\mathrm{AlCH}_{3}^{+}\right)$are shown in Fig. 4 as a function of the photolysis laser wavelength. The threshold for $\mathrm{Al}$ production is at about $255 \mathrm{~nm}$, whereas the $\mathrm{AlCH}_{3}$ yield has its onset at $230 \mathrm{~nm}$. For the case of resonant detection of the photoproducts $\mathrm{Al}$ and $\mathrm{AlCH}_{3}$ described in [6], the photolysis laser wavelength dependence of the yields is the same [20].

\section{Discussion}

Since the two-photon ionization probabilities of $\mathrm{Al}$ and $\mathrm{AlCH}_{3}$ are different, the relative ion yields must be calibrated in order to obtain the absolute yields $\mathrm{Y}(\mathrm{Al})$ and $\mathrm{Y}\left(\mathrm{AlCH}_{3}\right)$. The fact that only small amounts of $\mathrm{Al}\left(\mathrm{CH}_{3}\right)_{2}$ were detected [21], suggests a TMA decomposition mainly into the two channels $\mathrm{Al}$ plus organic fragments and $\mathrm{AlCH}_{3}$ plus organic fragments. Assuming TMA to have a purely dissociative transition in the region under investigation $(190-270 \mathrm{~nm})$, the sum of both fragmentation channels $[\mathrm{Y}(\mathrm{Al})+$ $\left.\mathrm{Y}\left(\mathrm{AlCH}_{3}\right)\right]$ should fit the absorption spectrum of TMA. Within our experimental accuracy this holds only for

$$
Y\left(\mathrm{AlCH}_{3}\right) / Y(\mathrm{Al})=1.5 \mathrm{Y}\left(\mathrm{AlCH}_{3}^{+}\right) / Y\left(\mathrm{Al}^{+}\right) \text {, }
$$

with the factor 1.5 compensating for the different ionization probabilities of $\mathrm{Al}$ and $\mathrm{AlCH}_{3}$ at $248 \mathrm{~nm}$ (Fig. 5).

The quantum yield is $\Phi_{x}:=N_{x} / N$, where $x$ stands for $\mathrm{Al}$ or $\mathrm{AlCH}_{3}, N_{x}$ is the number of photons in the $x$-channel and $\mathrm{N}$ is the total number of absorbed photons. From the proportionalities $Y_{x} \propto N_{x}$ and $A(\lambda) \propto N$, for an absorption coefficient $A$ much smaller than 1 , it follows that $\Phi_{x} \propto \mathbf{Y}_{x} / \mathbf{A}$.

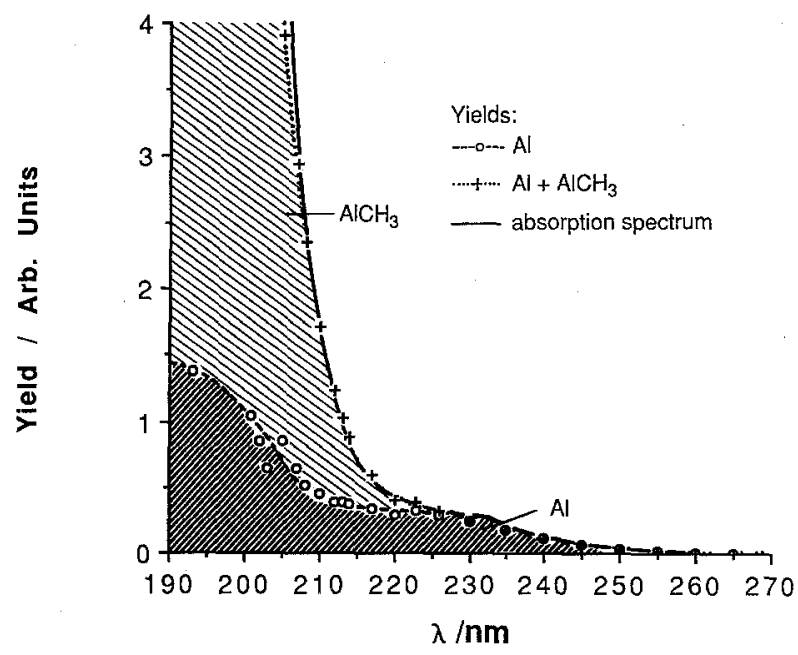

Fig. 5. The relative amounts of gaseous TMA decomposition products as a function of photolysis laser wavelength in comparison to the absorption spectrum

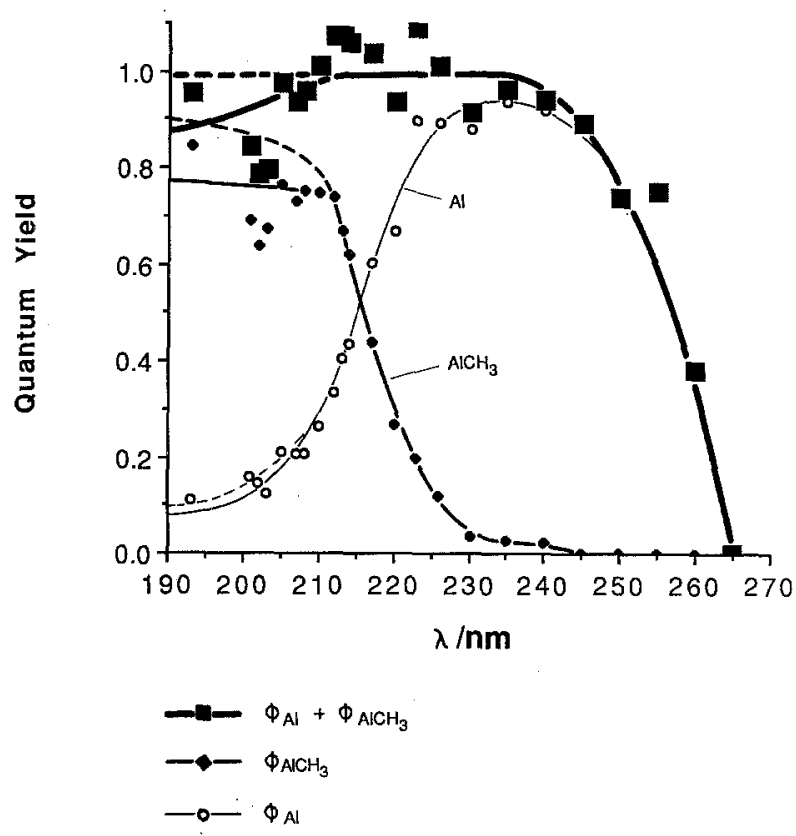

Fig. 6. Quantum yield $\Phi$ for the two fragmentation channels forming $\mathrm{Al}$ atoms and $\mathrm{AlCH}_{3}$ molecules and the sum of both. The yields were calculated from $\Phi=Y / A$, where $Y$ is the yield of a photoproduct and $A$ the measured absorption coefficient of TMA at 0.01 Torr (see text for details)

In Fig. 6 we have plotted the relative quantum yields $F_{x}=Y_{x} / A$ against the wavelength of the photolysis laser. Obviously the quantum yield for A1 production remains constant between 225 and $250 \mathrm{~nm}$. This means, that the decomposition of TMA in this interval predominantly leads to aluminum atoms and organic fragments. Below $230 \mathrm{~nm}$, the formation of $\mathrm{AlCH}_{3}$ molecules becomes more and more important, but both quantum yields sum up to a constant all the 
way down to $210 \mathrm{~nm}$. Below this value, the sum of both channels begins to decrease. A reason for this behaviour can be the uncertainty of the absorption spectrum for low pressures $(p<0.001$ Torr). Nevertheless, only small amounts of other photoproducts were detected in this region, so that we are confident that the dashed lines in Fig. 6 reflect the real photochemistry of TMA.

\section{Dissociation Mechanism of TMA}

One striking feature of our results is that aluminum atoms are produced at lower photon energies than $\mathrm{AlCH}_{3}$. Since the average bond energy of an $\mathrm{Al}-\mathrm{CH}_{3}$ bond in TMA is reported to be about $2.9 \mathrm{eV}$ [22], one expects $8.7 \mathrm{eV}$ to be necessary in order to separate all three $\mathrm{CH}_{3}$ ligands. On the other hand our experiments show that one $5 \mathrm{eV}$ photon is sufficient to isolate the $\mathrm{Al}$ atom. In order to explain the energy mismatch of $3.7 \mathrm{eV}$, we propose a mechanism which sets energy free:

$$
\left.\begin{array}{c}
\mathrm{Al}\left(\mathrm{CH}_{3}\right)_{3}+h v \stackrel{h<255 \mathrm{~nm}}{\longrightarrow} \mathrm{Al}\left(\mathrm{CH}_{3}\right)_{2}^{\dagger}+\mathrm{CH}_{3} \\
\mathrm{Al}\left(\mathrm{CH}_{3}\right)_{2}^{\dagger} \longrightarrow \mathrm{Al}+\mathrm{C}_{2} \mathrm{H}_{6} .
\end{array}\right\}
$$

The formation of $\mathrm{C}_{2} \mathrm{H}_{6}$ (ethane) as a direct photoproduct seems to be the only explanation for our surprising experimental results. Due to the high ionization potential of ethane $(11.6 \mathrm{eV})$, however, the collision free detection of $\mathrm{C}_{2} \mathrm{H}_{6}$ as a photoproduct is difficult with our present experimental setup.

The mechanism for the production of $\mathrm{AlCH}_{3}$ is:

$$
\mathrm{Al}\left(\mathrm{CH}_{3}\right)_{3}+h v \stackrel{\lambda<230 \mathrm{~nm}}{\longrightarrow} \mathrm{AlCH}_{3}+\mathrm{CH}_{3}+\mathrm{CH}_{3} \text {, }
$$

without the gain of energy through the formation of a stable molecule like $\mathrm{C}_{2} \mathrm{H}_{6}$. If TMA were to decompose via

$\mathrm{Al}\left(\mathrm{CH}_{3}\right)_{3}+h v \rightarrow \mathrm{AlCH}_{3}+\mathrm{C}_{2} \mathrm{H}_{6}$,

similar to the first mechanism (1), then $\mathrm{AlCH}_{3}$ should appear at lower photon energies than the $\mathrm{Al}$ atom. This is not the case (compare Fig. 4-6). Taking the average binding energy of $2.9 \mathrm{eV}$, one would expect the threshold for the $\mathrm{AlCH}_{3}$ production via the second process (2) at about $5.8 \mathrm{eV}$. Since for sequential removal of $\mathrm{CH}_{3}$ the second $\mathrm{Al}-\mathrm{C}$ bond in TMA is weaker than the first and third, due to unpairing of the two s-electrons in the aluminum atom [23], a red shift to a somewhat smaller value can be expected. This is in good agreement with the observed onset of the $\mathrm{AlCH}_{3}$ yield at $5.4 \mathrm{eV}$ $(230 \mathrm{~nm})$ (cf. Figs. 4-6).

Our results on TMG, trimethylgallium $\mathrm{Ga}\left(\mathrm{CH}_{3}\right)_{3}$, show that the wavelength dependence of the $\mathrm{Ga}$ and $\mathrm{GaCH}_{3}$ yields is similar to the case of TMA [24]. Additionally, we detected neutral In atoms after the photolysis of TMI (trimethylindium) at $308 \mathrm{~nm}(4 \mathrm{eV})$, although at least $5.3 \mathrm{eV}$ are necessary to break all three In-C bonds [22]. Therefore we conclude that TMA, TMG, and TMI all have the same dissociation mechanism.

\section{Conclusion}

We have shown that for gas phase TMA only the monomer absorbs UV light for $\lambda>220 \mathrm{~nm}$. The decomposition of TMA by UV laser light is a one-photon process with $\mathrm{Al}$ and $\mathrm{AlCH}_{3}$ as the main Al-containing photoproducts. The ratio $\left[\mathrm{AlCH}_{3}\right] /[\mathrm{Al}]$ is strongly wavelength dependent. This can be explained by the proposed dissociation mechanism given in (1) and (2).

Acknowledgements. We would like to acknowledge stimulating discussions with Y. Zhang, technical assistance by K. Müller and W. Sauermann, support by F. P. Schäfer, and financial support by SFB 93 (,Photochemie mit Lasern“, C2+C15) and BMFT (Nr. 13N5398/7).

\section{References}

1. T.F. Deutsch, D.J. Ehrlich, R.M. Osgood, Jr.: Appl. Phys. Lett. 35, 175 (1979)

2. D.J. Ehrlich, J.Y. Tsao: J. Vac. Sci. Technol. B 1, 969 (1983)

3. G.S. Higashi, C.G. Fleming: Appl. Phys. Lett. 48, 1051 (1986)

4. C. Jonah, P. Chandra, R. Bersohn: J. Chem. Phys. 55, 1903 (1971)

5. Y. Zhang, M. Stuke: J. Cryst. Growth 93, 143 (1988)

6. Y. Zhang, M. Stuke: Jap. J. Appl. Phys. 27, L1349 (1988)

7. Y. Zhang, M. Stuke: Chem. Phys. Lett. 149, 310 (1988)

8. Y. Zhang, Th. Beuermann, M. Stuke: Appl. Phys. B 48, 97 (1989)

9. S.A. Mitchell, P.A. Hackett: J. Chem. Phys. 79, 4815 (1983)

10. K. Ziegler, N.-R. Kroll, W. Larbig, O. Steudel: Ann. Chem. 629, 53 (1960)

11. R.W. Bigelow, J.G. Black, C.B. Duke, W.R. Salaneck, H.R. Thomas: Thin Solid Films 94, 233 (1982)

12. S. Okazaki: In Proceedings of the International Conference on Microlithography, Vienna 1988

13. K. Gamo, N. Takakura, N. Samoto, R. Shimizu, S. Namba: Jpn. J. Appl. Phys. 23, L239 (1984)

14. G.M. Shedd, H. Lezec, A.D. Dubner, J. Melngailis: Appl. Phys. Lett. 49, 1584 (1986)

15. W. Coburn, H.F. Winters, T.J. Chuang: J. Appl. Phys. 48, 3532 (1977)

16. T.M. Mayer, R.A. Barker, L.J. Whitman; J. Vac. Sci. Technol. B 4, 176 (1981)

17. R. Larciprete, M. Stuke: J. Phys. Chem. 90, 4586 (1986)

18. P. Lokai, B. Burkhardt, D. Basting, W. Mückenheim: Laser und Optoelektronik 3, 296 (1987)

19. C.H. Henrickson, D.P. Eyman: Inorg. Chem. 6, 1461 (1967)

20. Th. Beuermann, M. Stuke: Unpublished results

21. Th. Beuermann, M. Stuke: To be published

22. G. Pilcher, H.A. Skinner: In The Chemistry of the MetalCarbon Bond, ed. by F.R. Hartley, S. Patai (Wiley, New York 1982) Vol. 1, p. 69

23. W.A. Goddard III, L.B. Harding: Ann. Rev. Phys. Chem. 29, 363 (1978)

24. Th. Beuermann, M. Stuke: To be published 